\title{
THE RELATIONSHIP BETWEEN DOUBLE- $K$ PARAMETERS OF CONCRETE BASED ON FRACTURE EXTREME THEORY
}

\author{
YATONG NiE \\ School of Civil and Transportation Engineering, Hebei University of Technology, Tianjin, China, and \\ School of Civil and Environmental Engineering, UNSW Sydney, Australia \\ LONGBANG QING \\ School of Civil and Transportation Engineering, Hebei University of Technology, Tianjin, China \\ e-mail: qing@hebut.edu.cn
}

\begin{abstract}
The theoretical relationship between the initial fracture toughness and unstable fracture toughness in the double- $K$ model was established based on fracture extreme theory. Using this relationship, the initial fracture toughness and unstable fracture toughness can be obtained from each other without experimental measurement. The values of unstable fracture toughness of three-point bending concrete beams were calculated with the input of initial fracture toughness. The calculation was simplified by using the weight function method. The calculated results were compared with those obtained by the double- $K$ method. It is shown that the results obtained from these two methods show a good agreement. Unstable fracture toughness is affected by tensile strength and specimen size whereas unaffected by the ratio of initial crack length to depth. In addition, the softening function was found to have a negligible influence on the calculated result by a theoretical relationship.
\end{abstract}

Keywords: initial fracture toughness, unstable fracture toughness, theoretical relationship, simplified extreme method, softening function

\section{Introduction}

The application of linear elastic fracture mechanics (LEFM) to determine the fracture parameter of concrete was first introduced by Kaplan (1961). Since then, extensive research has been conducted to study the fracture process of quasi-brittle materials. The critical stress intensity factor calculated by LEFM mainly depends on specimen size (Bažant and Planas, 1998). This is due to the nonlinear fracture process zone at the crack tip, and indicates that LEFM is not applicable to concrete. To solve this problem, several nonlinear fracture models have been proposed to describe crack propagation in concrete, such as the fictitious crack model (Hillerborg et al., 1976), crack band model (Bažant and Oh, 1983), two parameter model (Jenq and Shah, 1985), size effect model (Bažant, 1984), effective crack model (Swartz and Go, 1984; Refai and Swartz, 1987; Karihaloo and Nallathambi, 1990), and double- $K$ model (Xu and Reinhardt, 1999a).

The double- $K$ model introduces initial fracture toughness $K_{I}^{i n i}$ and unstable fracture toughness $K_{I}^{u n}$ to characterize three different stages: crack initiation, stable crack propagation, and unstable fracture in concrete. The two fracture parameters can be obtained by performing different laboratory tests and can be applied to evaluate the safety of large-sized concrete structures, such as dams and nuclear power stations. $K_{I}^{i n i}$ represents the capability of resisting crack initiation. The value of $K_{I}^{i n i}$ can be calculated by initial cracking load $P^{i n i}$ and initial crack length $a_{0}$ using the formula of LEFM (Tada et al., 2000). $K_{I}^{u n}$ represents the maximum resistance to crack propagation, and its value can be calculated by inserting peak load $P_{\max }$ and critical 
crack length $a_{c}$ into the same formula of LEFM. $a_{c}$ is calculated by an LEFM expression based on the linear asymptotic superposition assumption containing critical crack mouth opening displacement $C M O D_{c}$ (Xu and Reinhardt, 1999b).

According to the double- $K$ method, the relationship between $K_{I}^{i n i}$ and $K_{I}^{u n}$ is established by the critical crack tip stress intensity factor due to the cohesive stress $K_{I}^{C}$, which is also called the cohesive toughness; thus, the following expression (Xu and Reinhardt, 1999b) is given

$$
K_{I}^{i n i}=K_{I}^{u n}-K_{I}^{C}
$$

$\mathrm{Xu}$ and Reinhardt (2000) adopted two empirical formulae to determine the values of $a_{c}$ and $K_{I}^{C}$, and thus simplify the calculation. In the simplified method, the special numerical technique to calculate $K_{I}^{C}$ in the analytical method (Xu and Reinhardt, 1999b) is not needed. Kumar and Barai (2009) adopted the weight function method and provided a closed form expression for calculating $K_{I}^{C}$. This method reduces the calculation complexity and provides accurate results. On the basis of the weight function method, Ince (2012) applied the peak load method (Tang et al., 1996) to determining the fracture parameters for the double- $K$ fracture model by using splitting test data for different specimen geometries. Kumar et al. (2014) proposed a method taking peak load as a parameter to calculate the double- $K$ fracture parameters. In this method, the measurement of $C M O D$ is not required; however, at least three different specimens are suggested to be used for a better estimation. Recently, Qing et al. (2017) developed a simplified extreme method using only experimental peak loads to obtain the double- $K$ fracture parameters. This method requires only one specimen to be tested and avoids the numerical integration.

Although the double- $K$ fracture parameters can be obtained from the above-mentioned methods, the theoretical relationship between the two parameters cannot be established due to the requirement of the test. Three-point bending beam tests are difficult to be conducted if the specimens are significantly large, and the influence of specimen weight cannot be ignored. Without the test data, $K_{I}^{\text {un }}$ can be obtained from $K_{I}^{i n i}$ by use of a few analytical methods (Qing et al., 2014; Wu et al., 2015). For example, on the basis of fracture extreme theory (Qing and Li, 2013), Qing et al. (2014) adopted the weight function method (Kumar and Barai, 2009) to successfully predict $K_{I}^{u n}$ with the input of $K_{I}^{i n i}$ based on the initial fracture toughness criterion (Dong et al., 2013). In this method, the values of the experimental peak loads and $C M O D_{c}$ are not required in the calculation due to the application of the extreme value theorem. Comparison of peak loads of wedge splitting specimens validates this approach for predicting the unstable fracture state of concrete. Analytical methods (Qing et al., 2014; Wu et al., 2015) can obtain $K_{I}^{u n}$ from $K_{I}^{i n i}$ but do not illustrate the theoretical relationship between the double- $K$ fracture parameters. Moreover, numerical integration needs to be used in these methods due to the singularity problem at the integral boundary.

The present study aims to establish the theoretical relationship between the double- $K$ fracture parameters based on the simplified extreme method. On the basis of this relationship, the initial fracture toughness and unstable fracture toughness of three-point bending beams can be obtained from each other without experimental measurement. The influences of the ratio of initial crack length to depth, concrete strength grade, and specimen size on the ratio of unstable fracture toughness to initial fracture toughness were studied.

\section{Theoretical method}

\subsection{Fracture extreme theory}

Figure 1 shows a typical $P-a / D$ ( $P$ is the external load, $a$ is the effective crack length, and $D$ is depth of the specimen) curve of concrete crack propagation. As can be seen, once the external load reaches the initial cracking load $P^{i n i}$, crack begins to propagate. This condition 
leads to the extension of crack length. When $P$ reaches the maximum value $P_{\max }, a$ equals to critical effective crack length $a_{c}$. The partial derivative of $P$ to $a$ at this critical stage can be expressed as

$$
\left.\frac{\partial P}{\partial a}\right|_{a=a_{c}}=0
$$

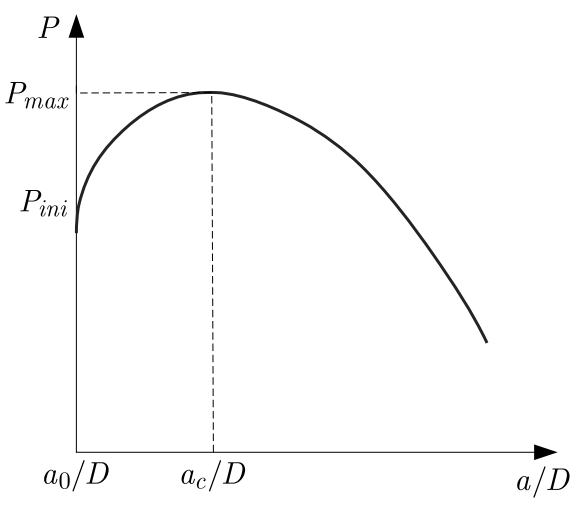

Fig. 1. Typical $P-a / D$ curve (Qing and Li, 2013)

\subsection{The relationship between double- $K$ parameters}

On the basis of the double- $K$ method (Xu and Reinhardt, 1999b), the values of the initial fracture toughness $K_{I}^{i n i}$ and unstable fracture toughness $K_{I}^{u n}$ for three-point bending beams with $S / D=4$ ( $S$ is the span of the specimen) are calculated as follows

$$
K_{I}=\frac{3(2 P+W) S}{4 B D^{2}} \sqrt{a} k(\alpha)
$$

where $B$ is width of the specimen, $\alpha=a / D, W$ is weight of the specimen and

$$
k(\alpha)=\frac{1.99-\alpha(1-\alpha)\left(2.15-3.93 \alpha+2.7 \alpha^{2}\right)}{(1+2 \alpha) \sqrt{(1-\alpha)^{3}}}
$$

When $\left(P_{\max }, a_{c}\right)$ is introduced into Eq. $(2.2)$, the following expression can be obtained

$$
P_{\max }=\frac{2 B D^{2}}{3 S \sqrt{a_{c}} k\left(\alpha_{c}\right)} K_{I}^{u n}-\frac{W}{2}
$$

The crack propagation criterion (Dong et al., 2013) is expressed as

$$
K_{I}^{i n i}=K_{I}^{P}-K_{I}^{\sigma}
$$

where $K_{I}^{P}$ is the stress intensity factor caused by the external load; $K_{I}^{\sigma}$ is the crack tip stress intensity factor due to the cohesive stress. Once the difference between $K_{I}^{P}$ and $K_{I}^{\sigma}$ equals to $K_{I}^{i n i}$, the crack begins to propagate.

In this study, numerical integration in the traditional analytical method was avoided by use of the weight function (Kumar and Barai, 2010), which is written as $K_{I}^{\sigma}=(2 / \sqrt{2 \pi a}) g(a)$, to calculate the value of $K_{I}^{\sigma}$. In the said equation, $g(a)$ is expressed in the four-term weight function as

$$
\begin{aligned}
& g(a)=\sigma(C T O D) a\left(2 \sqrt{s}+M_{1} s+\frac{2}{3} M_{2} \sqrt{s^{3}}+M_{3} s^{2}\right) \\
& \quad+\frac{f_{t}-\sigma(C T O D)}{a-a_{0}} a^{2}\left\{\frac{4}{3} \sqrt{s^{3}}+\frac{M_{1}}{2} s^{2}+\frac{4}{1} 5 M_{2} \sqrt{s^{5}}+\frac{M_{3}}{6}\left[1-\left(\frac{a_{0}}{a}\right)^{3}-3 s \frac{a_{0}}{a}\right]\right\}
\end{aligned}
$$


where $\sigma(C T O D)$ is the cohesive stress at the crack tip; CTOD is the crack tip opening displacement, $s=1-a_{0} / a, M_{1}, M_{2}$ and $M_{3}$ can be represented as polynomial expressions of $a / D$ (Kumar and Barai, 2010). Here, the cohesive stress is assumed to be distributed linearly along the cohesive zone. The cohesive stress at the initial crack and crack tip opening displacement $C T O D$ comply with the tensile softening curve, while the cohesive stress at the tip of the effective crack is equal to the tensile strength.

According to Eq. (2.4), the expression of external load $P$ can be derived as

$$
P=\frac{2 B D^{2}}{3 S \sqrt{a} k(\alpha)}\left[\frac{2}{\sqrt{2 \pi a}} g(a)+K_{I}^{i n i}\right]-\frac{W}{2}
$$

The derivative of $P$ to $a$ is obtained as follows

$$
\frac{\partial P}{\partial a}=\zeta^{\prime}(a)+\eta^{\prime}(a) K_{I}^{i n i}
$$

where

$$
\begin{aligned}
\zeta^{\prime}(a) & =\frac{4 B D^{2}}{3 \sqrt{2 \pi} S} \frac{g^{\prime}(a) k(\alpha) a-g(a)\left[k^{\prime}(\alpha) a+k(\alpha)\right]}{k^{2}(\alpha) a^{2}} \\
\eta^{\prime}(a) & =-\frac{2 B D^{2}}{3 S}\left[\frac{\frac{1}{\sqrt{a}} k(\alpha)+\sqrt{a} k^{\prime}(\alpha)}{2 a k^{2}(\alpha)}\right]
\end{aligned}
$$

$g^{\prime}(a)$ and $k^{\prime}(\alpha)$ are given in Appendix.

The following nonlinear softening function (Reinhardt et al., 1986) was used in the calculation

$$
\sigma(C T O D)=f_{t}\left\{\left[1+\left(\frac{c_{1} C T O D}{w_{0}}\right)^{3}\right] \exp \left(\frac{-c_{2} C T O D}{w_{0}}\right)-\frac{C T O D}{w_{0}}\left(1+c_{1}^{3}\right) \exp \left(-c_{2}\right)\right\}
$$

where $f_{t}$ is the tensile strength of concrete; $c_{1}, c_{2}$ and $w_{0}$ are material parameters.

For three-point bending notched beams, the following form (Jenq and Shah, 1985) was used to calculate $C T O D$

$$
C T O D=C M O D \sqrt{\left(1-\frac{a_{0}}{a}\right)^{2}+\left(-1.149 \frac{a}{D}+1.081\right)\left[\frac{a_{0}}{a}-\left(\frac{a_{0}}{a}\right)^{2}\right]}
$$

CMOD can be expressed by the formula of LEFM (Tada et al., 2000) for the three-point bending beam with $S / D=4$ as follows

$$
C M O D=\frac{6 P S a}{D^{2} B E}\left[0.76-2.28 \alpha+3.87 \alpha^{2}-2.04 \alpha^{3}+\frac{0.66}{(1-\alpha)^{2}}\right]
$$

Substituting $P=P_{\max }$ and $a=a_{c}$ into Eqs. (2.9) and (2.10) and combining Eq. (2.3) yields the critical crack tip opening displacement $C T O D_{c}$ expressed as follows

$$
\begin{gathered}
C T O D_{c}=\left(\frac{4 \sqrt{a_{c}} K_{I}^{u n}}{E k\left(\alpha_{c}\right)}-\frac{3 S a_{c} W}{D^{2} B E}\right)\left[0.76-2.28 \alpha_{c}+3.87 \alpha_{c}^{2}-2.04 \alpha_{c}^{3}+\frac{0.66}{\left(1-\alpha_{c}\right)^{2}}\right] \\
\cdot \sqrt{\left(1-\frac{a_{0}}{a_{c}}\right)^{2}+\left(-1.149 \frac{a_{c}}{D}+1.081\right)\left[\frac{a_{0}}{a_{c}}-\left(\frac{a_{0}}{a_{c}}\right)^{2}\right]}
\end{gathered}
$$

According to Eqs. (2.9) and (2.12), $\sigma\left(C T O D_{c}\right)$ was rewritten as the function of $K_{I}^{u n}$ and $a_{c}$ as follows

$$
\sigma\left(C T O D_{c}\right)=f_{1}\left(K_{I}^{u n}, a_{c}\right)
$$


When $P$ reaches $P_{\max }$, and $a=a_{c}$, substituting these into Eqs. (2.6) and (2.7) and combining Eqs. (2.12) and (2.13), a nonlinear equation system can be acquired as follows

$$
\begin{aligned}
& K_{I}^{u n}=K_{I}^{i n i}+\frac{2}{\sqrt{2 \pi a_{c}}} f_{1}\left(K_{I}^{u n}, a_{c}\right) a_{c}\left(2 \sqrt{s_{c}}+M_{1} s_{c}+\frac{2}{3} M_{2} \sqrt{s_{c}^{3}}+M_{3} s_{c}^{2}\right) \\
& +\frac{f_{t}-f_{1}\left(K_{I}^{u n}, a_{c}\right)}{a_{c}-a_{0}} a_{c}^{2}\left\{\frac{4}{3} \sqrt{s_{c}^{3}}+\frac{M_{1}}{2} s_{c}^{2}+\frac{4}{15} M_{2} \sqrt{s_{c}^{5}}+\frac{M_{3}}{6}\left[1-\left(\frac{a_{0}}{a_{c}}\right)^{3}-3 s \frac{a_{0}}{a_{c}}\right]\right\} \\
& \frac{4}{\sqrt{2 \pi}}\left[g^{\prime}\left(a_{c}\right) k\left(\alpha_{c}\right) a_{c}-g\left(a_{c}\right) k^{\prime}\left(\alpha_{c}\right) a_{c}-g\left(a_{c}\right) k\left(\alpha_{c}\right)\right] \\
& -\left[\sqrt{a_{c}} k\left(\alpha_{c}\right)+2 \sqrt{a_{c}^{3}} k^{\prime}\left(\alpha_{c}\right)\right] K_{I}^{i n i}=0
\end{aligned}
$$

The three unknowns in Eqs. (2.14) are $a_{c}, K_{I}^{i n i}$, and $K_{I}^{u n} \cdot a_{c}$ can be determined by solving the two above-mentioned equations if any one of $K_{I}^{i n i}$, and $K_{I}^{u n}$ is known. Thus, Eqs. (2.14) provides an implicit expression of the theoretical relationship between $K_{I}^{i n i}$ and $K_{I}^{u n}$. On the basis of the closed form expression, the values of initial fracture toughness and unstable fracture toughness can be obtained from each other without measurements of $C M O D_{c}$ and $P_{\max }$. This relationship indicates that the double- $K$ fracture parameters are mutually dependent.

\section{Validation and result}

The derived theoretical relationship was validated by taking the initial fracture toughness as a parameter to calculate the unstable fracture toughness. If the value of $K_{I}^{i n i}$ is given, Eqs. (2.14) provides two equations with two unknowns of $K_{I}^{u n}$ and $a_{c}$. By solving the nonlinear equations, the values of $K_{I}^{u n}$ and $a_{c}$ can be obtained.

The data of two series of three-point bending notched beams with different ratios of initial crack length to depth (Refai and Swartz, 1987) and different concrete strength grades (Dong et al., 2016; Wang et al., 2016) were used for validation of the theoretical relationship.

Specimens with different ratios of initial crack length to depth were denoted as $B$-series as in Refai and Swartz (1987). The dimensions for $B$-series specimens are $76 \mathrm{~mm} \times 203 \mathrm{~mm} \times 760 \mathrm{~mm}$ (BDS). The cylinder compressive strength $f_{c}$ of concrete is $53.1 \mathrm{MPa}$, and Young's modulus of concrete $E$ is $38.4 \mathrm{GPa}$, the maximum aggregate size $d_{\max }=19 \mathrm{~mm}$ The initial fracture toughness $K_{I}^{\text {ini }}$ was calculated by the double- $K$ method.

Specimens with different grades of concrete strength were denoted as TPB-series as in Dong et al. (2016) and Wang et al. (2016). The dimensions for TPB-series are $60 \mathrm{~mm} \times 120 \mathrm{~mm} \times 480$ $\mathrm{mm}(B \times D \times S)$, and the ratios of initial crack length to depth $a_{0} / D$ are all 0.3 . The tensile strength $f_{t}$ was computed by using the relation $f_{t}=0.4983 \sqrt{f_{c}}$ (ACI-318, 2002; Karihaloo and Nallathambi, 1991). The initial cracking load was obtained by strain gauges, and then the initial fracture toughness was calculated by the formula of LEFM (Tada et al., 2000). Detailed parameters of the specimens are presented in Tables 1 and 2.

Kumar and Barai (2012) studied the size effect of concrete based on finite element method (FEM). The results of three-point bending beams with different specimen sizes were used as an example to validate the developed theoretical relationship. These specimens were denoted as SE-series in this study. The width $B$ of specimens is $100 \mathrm{~mm}$, and $S / D=4$. The ratios of initial crack length to depth for SE-series specimens are in the range of 0.2 to 0.5. The concrete has mechanical properties as $f_{t}=3.21 \mathrm{MPa}$ and $E=30 \mathrm{GPa}$, and the fracture energy $G_{F C}=103 \mathrm{~N} / \mathrm{m}$ (Planas and Elices, 1990).

The material constants $c_{1}=3, c_{2}=7$, and $w_{0}=160 \mu \mathrm{m}$ (Reinhardt et al., 1986) were taken into Eq. (2.9) to calculate $K_{I}^{\sigma}$. 
Table 1. Parameters and comparison of the results of $B$-series specimens $\left(f_{c}=53.1 \mathrm{MPa}, E=38.4 \mathrm{GPa}\right.$, and $\left.d_{\max }=19 \mathrm{~mm}\right)$

\begin{tabular}{|c|c|c|c|c|c|c|c|c|}
\hline \multirow{2}{*}{$\begin{array}{c}\text { Speci- } \\
\text { men } \\
\text { No. }\end{array}$} & \multirow[b]{2}{*}{$a_{0} / D$} & \multirow[b]{2}{*}{$\begin{array}{c}K_{I}^{i n i} \\
{[\mathrm{MPa} \sqrt{m}]}\end{array}$} & \multicolumn{2}{|c|}{$C M O D_{c}[\mu \mathrm{m}]$} & \multicolumn{2}{|c|}{$P_{\max }[\mathrm{kN}]$} & \multicolumn{2}{|l|}{$K_{I}^{u n}[\mathrm{MPa} \sqrt{m}]$} \\
\hline & & & $\begin{array}{l}\text { Test result (Refai } \\
\text { and Swartz, 1987) }\end{array}$ & \begin{tabular}{|c|c|}
$\begin{array}{c}\text { Calculated } \\
\text { result }\end{array}$ \\
\end{tabular} & $\begin{array}{l}\text { Test result (Refai } \\
\text { and Swartz, 1987) }\end{array}$ & $\begin{array}{c}\text { Calculated } \\
\text { result }\end{array}$ & $\begin{array}{c}\text { Double- } K \text { method } \\
(\mathrm{Xu} \text { and Reinhardt, 1999b) }\end{array}$ & $\begin{array}{c}\text { Calculated } \\
\text { result }\end{array}$ \\
\hline$\overline{\mathrm{B} 16}$ & 0.309 & $\overline{0.51}$ & 44 & $\overline{51.6}$ & 5.79 & $\overline{c 6.02}$ & 1.358 & 1.493 \\
\hline B4 & 0.319 & 0.507 & 43.4 & 52.2 & 5.612 & 5.837 & 1.33 & 1.482 \\
\hline B17 & 0.362 & 0.563 & 53.3 & 57.3 & 5.166 & 5.31 & 1.436 & 1.497 \\
\hline B15 & 0.376 & 0.622 & 43.1 & 58.5 & 5.033 & 5.273 & 1.264 & 1.51 \\
\hline B1 & 0.383 & 0.795 & 45.9 & 59.2 & 5.523 & 5.725 & 1.361 & 1.576 \\
\hline B3 & 0.442 & 0.709 & 51.1 & 63.4 & 4.365 & 4.503 & 1.308 & 1.48 \\
\hline B20 & 0.459 & 0.716 & 61.4 & 65.3 & 4.187 & 4.272 & 1.43 & 1.474 \\
\hline B18 & 0.478 & 0.766 & 65.5 & 67.2 & 4.053 & 4.128 & 1.468 & 1.478 \\
\hline B19 & 0.495 & 0.822 & 58 & 69.4 & 3.919 & 4.028 & 1.349 & 1.491 \\
\hline B5 & 0.588 & 0.883 & 89.5 & 77.6 & 3.207 & 3.31 & 1.634 & 1.478 \\
\hline B8 & 0.636 & 0.828 & 80 & 85.7 & 2.227 & 2.287 & 1.354 & 1.372 \\
\hline B7 & 0.648 & 0.992 & 89.4 & 90.4 & 2.249 & 2.416 & 1.457 & 1.448 \\
\hline B10 & 0.654 & 0.818 & 77.4 & 88 & 2.004 & 2.084 & 1.286 & 1.35 \\
\hline B9 & 0.706 & 0.843 & 92.8 & 94.1 & 1.537 & 1.615 & 1.346 & 1.407 \\
\hline Avg. & - & - & 63.9 & 70 & 3.919 & 4.058 & 1.384 & 1.467 \\
\hline S.D. & - & - & 18.6 & 14.6 & 1.455 & 1.502 & 0.095 & 0.058 \\
\hline C.V. & - & - & $29.03 \%$ & $20.84 \%$ & $37.12 \%$ & $37.03 \%$ & $6.86 \%$ & $3.93 \%$ \\
\hline
\end{tabular}

Table 2. Parameters and comparison of the results of TPB-series specimens

\begin{tabular}{|c|c|c|c|c|c|c|c|c|c|}
\hline \multirow[b]{2}{*}{$\begin{array}{l}\text { Specimen } \\
\text { No. }\end{array}$} & \multirow{2}{*}{$\begin{array}{l}\text { Concrete } \\
\text { strength } \\
\text { grade }\end{array}$} & \multirow[b]{2}{*}{$\begin{array}{c}f_{c} \\
{[\mathrm{MPa}]}\end{array}$} & \multirow[b]{2}{*}{$\begin{array}{c}E \\
{[\mathrm{GPa}]}\end{array}$} & \multirow[b]{2}{*}{$\begin{array}{l}d_{\max } \\
{[\mathrm{mm}]}\end{array}$} & \multirow{2}{*}{$\begin{array}{c}K_{I}^{i n i} \\
{[\mathrm{MPa} \sqrt{m}]}\end{array}$} & \multicolumn{2}{|c|}{$P_{\max }[\mathrm{kN}]$} & \multicolumn{2}{|c|}{$K_{I}^{u n}[\mathrm{MPa} \sqrt{m}]$} \\
\hline & & & & & & $\begin{array}{c}\text { Test results } \\
\text { (Wang et al., 2016) }\end{array}$ & $\begin{array}{l}\text { Calculated } \\
\text { result }\end{array}$ & $\begin{array}{l}\text { Double- } K \text { Method } \\
\text { (Dong et al., 2016) }\end{array}$ & $\begin{array}{l}\text { Calculated } \\
\text { result }\end{array}$ \\
\hline 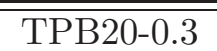 & 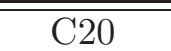 & "32.8 & 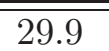 & $\overline{20}$ & "0.461 & 2.485 & 2.57 & $\overline{~ 1.127}$ & $\bar{~} 1.031$ \\
\hline TPB40-0.3 & $\mathrm{C} 40$ & 48.9 & 33.2 & 20 & 0.616 & 3.283 & 3.241 & 1.445 & 1.275 \\
\hline TPB60-0.3 & C60 & 69.9 & 35.7 & 20 & 0.632 & 3.501 & 3.601 & 1.463 & 1.445 \\
\hline TPB80-0.3 & $\mathrm{C} 80$ & 84.1 & 38.1 & 20 & 0.667 & 3.806 & 3.882 & 1.406 & 1.588 \\
\hline TPB100-0.3 & C100 & 115.8 & 41.1 & 16 & 0.917 & 4.761 & 4.835 & 1.751 & 1.866 \\
\hline
\end{tabular}




\subsection{Comparison of peak load}

The calculated and tested peak loads for $B$-series (Refai and Swartz, 1987) and TPB-series (Wang et al., 2016) are listed in Tables 1 and 2, respectively. The comparison of peak loads is shown in Fig. 2. As can be seen, the calculated peak loads are slightly higher than the tested ones for the $B$-series specimens (Refai and Swartz, 1987), while the differences are no more than 5\%. For the TPB-series specimens (Wang et al., 2016), the calculated results match the tested results well. The good agreement indicates that unstable fracture toughness can be obtained satisfactorily using the given theoretical relationship.
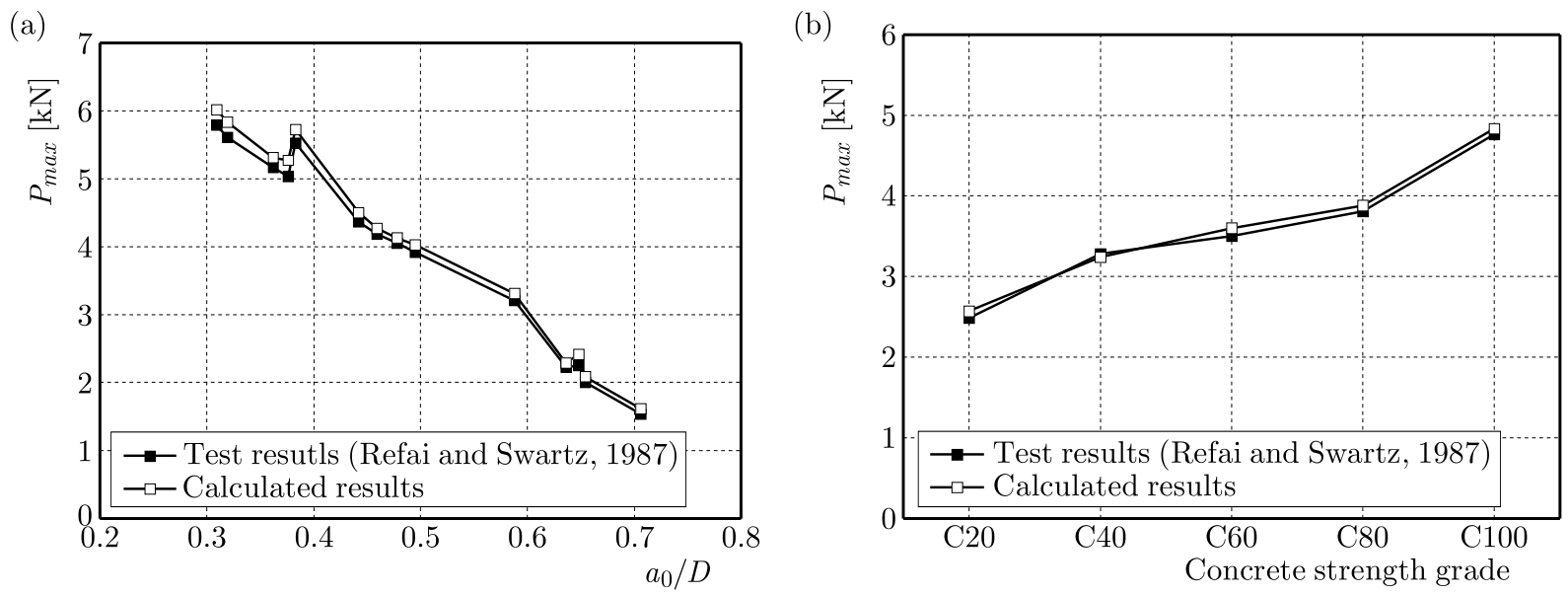

Fig. 2. Comparison of calculated and tested peak loads: (a) B-series, (b) TPB-series

Table 3 shows the comparison of $P_{\max }$ obtained using the theoretical relationship with those obtained by FEM. As shown in Table 3, there is not much difference (within the accuracy of 15\%) between the values of $P_{\max }$ calculated by the theoretical relationship with those calculated by FEM. This means that the method based on the theoretical relationship could produce a reasonable result as the specimen size varies from $100 \mathrm{~mm}$ to $400 \mathrm{~mm}$.

\subsection{Unstable fracture toughness predicted using the theoretical relationship}

Tables 1 and 2 show the calculated results of the unstable fracture toughness $K_{I}^{u n}$, respectively. In these tables, the values of $K_{I}^{u n}$ in Xu and Reinhardt (1999b) and Dong et al. (2016) are obtained by the double- $K$ method. It can be seen that except for specimen "B15", the values of $K_{I}^{u n}$ obtained by using the theoretical relationship agree with the corresponding values obtained by the double- $K$ method within $15 \%$ accuracy. For specimen "B15", the ratio of the value of $K_{I}^{u n}$ calculated by the theoretical relationship to that by the double- $K$ method is 1.194 . Since the values of $P_{\max }$ are similar in the two methods, the relatively lower value of $K_{I}^{u n}$ calculated by the double- $K$ method is attributed to the inaccuracy of the tested $C M O D_{c}$. Compared to the double- $K$ method, the method based on the theoretical relationship is more simple and easier to operate.

Given that the results of $K_{I}^{u n}$ obtained by the theoretical relationship are in good agreement with those by the double- $K$ method, the results of the two methods were chosen for the subsequent analysis. Figure 3a shows the variation of unstable fracture toughness with $a_{0} / D$ for $B$-series specimens. It can be seen that the values of unstable fracture toughness vary slightly as $a_{0} / D$ increases. Therefore, it can be concluded that $a_{0} / D$ has no significant influence on $K_{I}^{u n}$. This result is similar to the effect observed by Xu and Reinhardt (1999c). 
Table 3. Comparison of the results obtained by FEM and the theoretical relationship $\left(f_{t}=3.21 \mathrm{MPa}, E=30 \mathrm{GPa}\right.$, and $\left.G_{F C}=103 \mathrm{~N} / \mathrm{m}\right)$

\begin{tabular}{|c|c|c|c|c|c|c|c|c|c|}
\hline \multirow[b]{2}{*}{$\begin{array}{l}\text { Speci- } \\
\text { men } \\
\text { No. }\end{array}$} & \multirow[b]{2}{*}{$\begin{array}{c}D \\
{[\mathrm{~mm}]}\end{array}$} & \multirow[b]{2}{*}{$a_{0} / D$} & \multirow[b]{2}{*}{$\begin{array}{c}K_{I}^{i n i} \\
{[\mathrm{MPa} \sqrt{m}]}\end{array}$} & \multicolumn{3}{|c|}{$P_{\max }[\mathrm{kN}]$} & \multicolumn{3}{|c|}{$K_{I}^{u n}[\mathrm{MPa} \sqrt{m}]$} \\
\hline & & & & $\begin{array}{l}\text { FEM result } \\
\text { (Kumar and } \\
\text { Barai, 2012) }\end{array}$ & $\begin{array}{l}\text { Calculated } \\
\text { result } \\
\text { (nonlinear) }\end{array}$ & $\begin{array}{c}\text { Calculated } \\
\text { result } \\
\text { (quasi-exponent.) }\end{array}$ & $\begin{array}{c}\text { Double- } K \text { method } \\
\text { (Kumar and } \\
\text { Barai, 2012) }\end{array}$ & $\begin{array}{c}\text { Calculated } \\
\text { result } \\
\text { (nonlinear) }\end{array}$ & $\begin{array}{c}\text { Calculated } \\
\text { result } \\
\text { (quasi-exponent.) }\end{array}$ \\
\hline 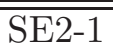 & 100 & 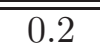 & 0.553 & 5070.94 & 5669.85 & 5808.46 & 1.224 & 1.122 & 1.198 \\
\hline SE2-2 & 200 & 0.2 & 0.547 & 8502.8 & 9266.80 & 9555.46 & 1.328 & 1.353 & 1.395 \\
\hline SE2-3 & 300 & 0.2 & 0.532 & 11276.59 & 12392.34 & 12730.04 & 1.400 & 1.541 & 1.519 \\
\hline SE2-4 & 400 & 0.2 & 0.520 & 13608.21 & 15384.23 & 15627.64 & 1.419 & 1.766 & 1.649 \\
\hline SE3-1 & 100 & 0.3 & 0.572 & 3934.5 & 4391.15 & 4497.42 & 1.238 & 1.113 & 1.185 \\
\hline SE3-2 & 200 & 0.3 & 0.565 & 6571.4 & 7128.94 & 7339.38 & 1.316 & 1.331 & 1.370 \\
\hline SE3-3 & 300 & 0.3 & 0.554 & 8672.38 & 9544.79 & 9766.93 & 1.377 & 1.545 & 1.519 \\
\hline SE3-4 & 400 & 0.3 & 0.539 & 10405 & 11819.95 & 11945.31 & 1.420 & 1.763 & 1.609 \\
\hline SE4-1 & 100 & 0.4 & 0.576 & 2947.2 & 3280.91 & 3358.56 & 1.212 & 1.067 & 1.134 \\
\hline SE4-2 & 200 & 0.4 & 0.576 & 4909.7 & 5325.16 & 5473.15 & 1.299 & 1.299 & 1.335 \\
\hline $\begin{array}{l}\text { SE4-3 } \\
\text { nat }\end{array}$ & 300 & 0.4 & 0.566 & 6447.9 & 7116.82 & 7262.31 & 1.383 & 1.503 & 1.475 \\
\hline SE4-4 & 400 & 0.4 & 0.553 & 7683.4 & 8806.06 & 8873.98 & 1.416 & 1.677 & 1.561 \\
\hline SE5-1 & 100 & 0.5 & 0.575 & 2095.2 & 2352.11 & 2404.43 & 1.188 & 1.018 & 1.079 \\
\hline SE5-2 & 200 & 0.5 & 0.578 & 3477.2 & 3803.48 & 3903.89 & 1.281 & 1.232 & 1.265 \\
\hline SE5-3 & 300 & 0.5 & 0.572 & 4529.49 & 5078.35 & 5177.37 & 1.351 & 1.424 & 1.397 \\
\hline SE5-4 & 400 & 0.5 & 0.562 & 5335.2 & 6274.96 & 6323.69 & 1.370 & 1.585 & 1.507 \\
\hline
\end{tabular}


(a)

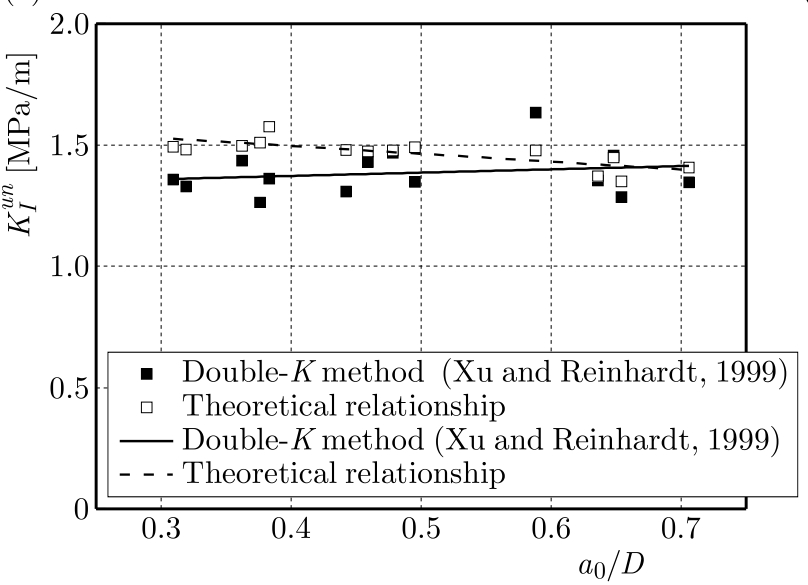

(b)

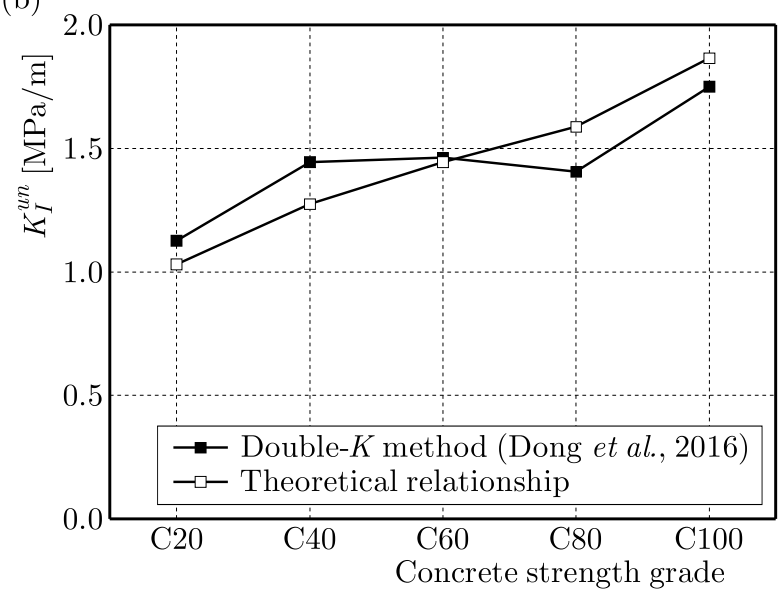

Fig. 3. Variation of unstable fracture toughness with $a_{0} / D(\mathrm{a})$ and with concrete strength grade (b)

Figure $3 \mathrm{~b}$ shows the variation of $K_{I}^{u n}$ with the concrete strength grade for TPB-series specimens. It can be noticed that when the concrete strength grade is lower than approximately C60, the values of $K_{I}^{u n}$ calculated by the double- $K$ method are greater than those calculated by the theoretical relationship. However, this tendency is opposite as the concrete strength grade is over C60. In general, the values of $K_{I}^{u n}$ increase with the concrete strength. This result is consistent with that found by Kumar and Barai (2009).

Figure 4 compares the values of $K_{I}^{u n}$ determined by the theoretical relationship with those obtained by FEM (Kumar and Barai, 2012) for SE-series specimens with $a_{0} / D=0.3$. It can be seen from Fig. 4 that the values of $K_{I}^{u n}$ obtained by the method based on theoretical relationship are close to those obtained by FEM as the specimen size varies from $100 \mathrm{~mm}$ to $400 \mathrm{~mm}$. The unstable fracture toughness shows an increase trend as the specimen size increases. Table 3 indicates that for different values of $a_{0} / D$, the variations of $K_{I}^{u n}$ with the specimen size are similar. This means that $K_{I}^{u n}$ is not influenced by $a_{0} / D$.

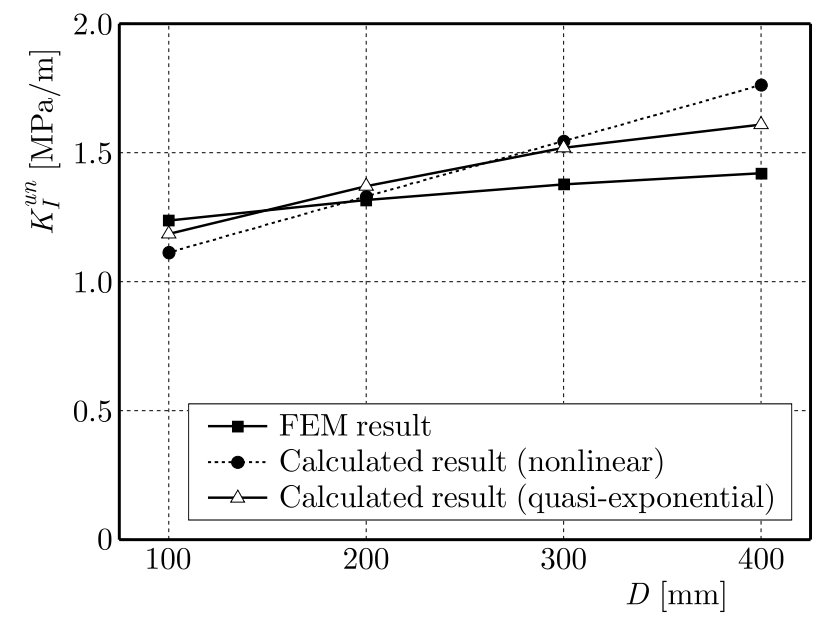

Fig. 4. Comparison of unstable fracture toughness obtained by the theoretical relationship with that obtained by FEM for a specimen of $a_{0} / D=0.3$

\section{Influence of softening functions}

To study the effect of softening functions on the method based on the theoretical relationship, a quasi-exponential softening function (Planas and Elices, 1990) was used to calculate the fracture 
toughness of specimens from Kumar and Barai (2012). The quasi-exponential softening function is characterized by the following expression

$$
\sigma(C T O D)= \begin{cases}f_{t}\left[\left(1+b_{1}\right) \exp \left(\frac{-b_{2} w f_{t}}{G_{F C}}\right)-b_{1}\right] & \text { for } \quad 0<w \leqslant \frac{5 G_{F C}}{f_{t}} \\ 0 & \text { for } \quad \frac{5 G_{F C}}{f_{t}} \leqslant w\end{cases}
$$

$$
b_{1}=0.0082896 \quad b_{2}=0.96020
$$

where $b_{1}$ and $b_{2}$ are material constants.

The calculated results for the peak load and unstable fracture toughness using the quasi-exponential softening function are presented in Table 3. The values of unstable fracture toughness using the quasi-exponential softening function for SE-series specimens with $a_{0} / D=0.3$ were added in Fig. 4. It is observed that the results obtained using the quasi-exponential softening function are very close (within the accuracy of $8 \%$ ) to those obtained using the nonlinear softening. Furthermore, all the calculated results show that the unstable fracture toughness increases with the specimen size. It is evident that concrete shows higher resistance to unstable fracture as the specimen becomes larger.

\section{Conclusion}

The theoretical relationship between the initial fracture toughness and unstable fracture toughness was established. An implicit closed form expression of the relationship between the two parameters was given. Based on the theoretical relationship, the double- $K$ fracture parameters can be obtained from each other without experimental measurement.

The developed theoretical relationship was validated by the method with the input of the initial fracture toughness to calculate the unstable fracture toughness. Results show that the values of the unstable fracture toughness obtained by the theoretical relationship agree with those obtained by the double- $K$ method and the finite element method. The unstable fracture toughness increases with the specimen size and concrete strength, whereas it shows no appreciable difference when the ratio of initial crack length to depth varies.

The influence of softening functions on the method based on the theoretical relationship is studied. Results show that the calculated values of the peak load and unstable fracture toughness obtained by the nonlinear softening function and the quasi-exponential softening function are close to each other.

\section{A. Appendix}

$g^{\prime}(a)$ and $k^{\prime}(\alpha)$ in Eqs. (2.8) can be expressed as follows

$$
\begin{gathered}
k^{\prime}(\alpha)=\frac{1}{D\left(1+2 \alpha^{2}\right)(1-\alpha)^{3}}\left\{\left(-2.15+12.16 \alpha-19.89 \alpha^{2}+10.8 \alpha^{3}\right)(1+2 \alpha) \sqrt{(1-\alpha)^{3}}\right. \\
\left.-\left(1.99-2.15 \alpha+6.08 \alpha^{2}-6.63 \alpha^{3}+2.7 \alpha^{4}\right)\left[2 \sqrt{(1-\alpha)^{3}}-\frac{3}{2}(1+2 \alpha) \sqrt{(1-\alpha)}\right]\right\}
\end{gathered}
$$




$$
\begin{aligned}
& g^{\prime}(a)=\left(A_{1}+A_{1}^{\prime} a\right)\left(2 \sqrt{s}+M_{1} s+\frac{2}{3} M_{2} \sqrt{s^{3}}+\frac{1}{2} M_{3} s^{2}\right) \\
& +A_{1} a\left(\frac{1}{\sqrt{s}} s^{\prime}+M_{1} s^{\prime}+M_{1}^{\prime} s+M_{2} \sqrt{s} s^{\prime}+\frac{2}{3} M_{2}^{\prime} \sqrt{s^{3}}+M_{3} s s^{\prime}+\frac{1}{2} M_{3}^{\prime} s\right) \\
& +A_{2} a^{2}\left[2 \sqrt{s} s^{\prime}+M_{1} s s^{\prime}+\frac{M_{1}^{\prime}}{2} s+\frac{2}{3} M_{2} \sqrt{s^{3}} s^{\prime}+\frac{4}{15} M_{2}^{\prime} \sqrt{s^{5}}\right. \\
& \left.+\frac{M_{3}}{2}\left(\frac{a_{0}^{3}}{a^{4}}-s^{\prime} \frac{a_{0}}{a}+s \frac{a_{0}}{a^{2}}\right)\right]+A_{2} a^{2}\left\{\frac{M_{3}^{\prime}}{6}\left[1-\left(\frac{a_{0}}{a}\right)^{3}-3 s \frac{a_{0}}{a}\right]\right\} \\
& +\left(2 A_{2} a+A_{2}^{\prime} a^{2}\right)\left\{\frac{4}{3} \sqrt{s^{3}}+\frac{M_{1}}{2} s^{2}+\frac{4}{15} M_{2} \sqrt{s^{5}}+\frac{M_{3}}{6}\left[1-\left(\frac{a_{0}}{a^{\prime}}\right)^{3}-3 s \frac{a_{0}}{a}\right]\right\}
\end{aligned}
$$

where

$$
\begin{aligned}
& s^{\prime}=\frac{a_{0}}{a^{2}} \\
& A_{1}^{\prime}=\frac{\partial \sigma(C T O D)}{\partial a}=\frac{\partial \sigma(C T O D)}{\partial C T O D} \frac{\partial C T O D}{\partial a} \\
& A_{2}^{\prime}=\frac{-\sigma^{\prime}(C T O D)\left(a-a_{0}\right)-\left[f_{t}-\sigma(C T O D)\right]}{\left(a-a_{0}\right)^{2}}
\end{aligned}
$$

for $i=1$ and 3

$$
\begin{aligned}
M_{i}^{\prime} & =\frac{1}{\sqrt{(1-a / D)^{3}}}\left(\frac{b_{i}}{D}+2 c_{i} \frac{a}{D^{2}}+3 d_{i} \frac{a^{2}}{D^{3}}+4 e_{i} \frac{a^{3}}{D^{4}}+5 f_{i} \frac{a^{4}}{D^{5}}\right) \\
& +\frac{3}{2 D} \frac{1}{\sqrt{(1-a / D)^{5}}}\left[a_{i}+b_{i} \frac{a}{D}+c_{i}\left(\frac{a}{D}\right)^{2}+d_{i}\left(\frac{a}{D}\right)^{3}+e_{i}\left(\frac{a}{D}\right)^{4}+f_{i}\left(\frac{a}{D}\right)^{5}\right] \\
M_{2}^{\prime} & =\frac{b_{i}}{D}
\end{aligned}
$$

According to Eq. (2.9)

$$
\begin{array}{r}
\frac{\partial \sigma(C T O D)}{\partial C T O D}=f_{t}\left\{\frac { 3 c _ { 1 } } { w _ { 0 } } \operatorname { e x p } ( - \frac { c _ { 2 } C T O D } { w _ { 0 } } ) \left[\left(\frac{c_{1} C T O D}{w_{0}}\right)^{2}\right.\right. \\
\left.\left.-\frac{c_{2}}{w_{0}}\left(1+\left(\frac{c_{1} C T O D}{w_{0}}\right)^{3}\right)\right]-\frac{1}{w_{0}}\left(1+c_{1}^{3}\right) \exp \left(-c_{2}\right)\right\}
\end{array}
$$

Substituting Eq. (2.10) to Eq. (2.9), the expression of $\partial C T O D / \partial a$ can be obtained

$$
\begin{aligned}
& \frac{\partial C T O D}{\partial a}=\frac{6 P S}{B D^{2} E}\left[0.76-4.56 \alpha+11.61 \alpha^{2}-8.16 \alpha^{3}+\frac{0.66}{(1-\alpha)^{2}}+\frac{1.32 \alpha}{(1-\alpha)^{3}}\right] \\
& \cdot\left\{s^{2}+(1.081-1.149 \alpha)\left[\frac{a_{0}}{a}-\left(\frac{a_{0}}{a}\right)^{2}\right]\right\}^{1 / 2} \\
& +\frac{3 P S a}{B D^{2} E}\left[0.76-2.28 \alpha+3.87 \alpha^{2}-2.04 \alpha^{3}+\frac{0.66}{(1-\alpha)^{2}}\right] \\
& \cdot\left\{s^{2}+(1.081-1.149 \alpha)\left[\frac{a_{0}}{a}-\left(\frac{a_{0}}{a}\right)^{2}\right]\right\}^{-1 / 2} \\
& \cdot\left\{2 s s^{\prime}-\frac{1.149}{D}\left[\frac{a_{0}}{a}-\left(\frac{a_{0}}{a}\right)^{2}\right]-(1.081-1.149 \alpha)\left(\frac{a_{0}}{a^{2}}-2 \frac{a_{0}^{2}}{a^{3}}\right)\right\}
\end{aligned}
$$

Acknowledgements

The work presented in the paper was supported by the National Natural Science Foundation of China (No. 51779069) and the Open Research Fund of State Key Laboratory of Simulation and Regulation of Water Cycle in River Basin (IWHR-SKL-201618). 


\section{References}

1. ACI-318, 2002, Building code requirements for structural concrete and commentary, Michigan: Farmington Hills

2. BAŽAnt Z.P., 1984, Size effect in blunt fracture: concrete, rock, metal, Journal of Engineering Mechanics, 110, 518-535

3. BAžAnt Z.P., Он B.H., 1983, Crack band theory for fracture of concrete, Materials and Structures, 16, 3, 155-177

4. Bažant Z.P., Planas J., 1998, Fracture and Size Effect in Concrete and Other Quasibrittle Materials, CRC Press, Boca Raton, FL

5. Dong W., Wu Z.M., Zhou X.M., 2013, Calculating crack extension resistance of concrete based on a new crack propagation criterion, Construction and Building Materials, 38, 2, 879-889

6. Dong W., Wu Z., Zhou X., Wang C., 2016, A comparative study on two stress intensity factor-based criteria for prediction of mode-I crack propagation in concrete, Engineering Fracture Mechanics, 158, 39-58

7. Hillerborg A., Modéer M., Petersson P.E., 1976, Analysis of crack formation and crack growth in concrete by means of fracture mechanics and finite elements, Cement Concrete Research, 6, 6, 773-781

8. INCE R., 2012, Determination of the fracture parameters of the Double- $K$ model using weight functions of split-tension specimens, Engineering Fracture Mechanics, 96, 416-432

9. Jenq Y.S., Shah S.P., 1985, Two parameter fracture model for concrete, Journal of Engineering Mechanics, 111, 10, 1227-1241

10. Kaplan M.F., 1961, Crack propagation and the fracture of concrete, Journal of the American Concrete Institute, 58, 11, 591-610

11. Karihaloo B.L., Nallathambi P., 1990, Effective crack model for the determination of fracture toughness (KICe) of concrete, Engineering Fracture Mechanics, 35, 637-645

12. Karihaloo B.L., Nallathambi P., 1991, Notched beam test: mode I fracture toughness, fracture mechanics test methods for concrete, [In:] Fracture Mechanics Test Methods for Concrete. Report of RILEM Technical Committee 89-FMT, Shap S.P and Carpinteri A. (Edit.), Chapman \& Hall, London

13. Kumar S., Barai S.V., 2009, Determining double- $K$ fracture parameters of concrete for compact tension and wedge splitting tests using weight function, Engineering Fracture Mechanics, 76, 935-948

14. Kumar S., Barai S.V., 2010, Determining the double- $K$ fracture parameters for three-point bending notched concrete beams using weight function, Fatigue and Fracture of Engineering Materials and Structure, 33, 10, 645-660

15. Kumar S., Barai S.V., 2012, Size-effect of fracture parameters for crack propagation in concrete: a comparative study, Computers and Concrete, 9, 1, 1-19

16. Kumar S., Pandey S.R., Srivastava A.K.L., 2014, Determination of double- $K$ fracture parameters of concrete using peak load method, Engineering Fracture Mechanics, 131, 471-484

17. Planas J., Elices M., 1990, Fracture criteria for concrete: Mathematical validations and experimental validation, Engineering Fracture Mechanics, 35, 87-94

18. Qing L.B., Li Q.B., 2013, A theoretical method for determining initiation toughness based on experimental peak load, Engineering Fracture Mechanics, 99, 295-305

19. Qing L.B., Nie Y.T., Wang J., Hu Y., 2017, A simplified extreme method for determining double- $K$ fracture parameters of concrete using experimental peak load, Fatigue and Fracture of Engineering Materials and Structure, 40, 254-266 
20. Qing L.B., Tian W.L., Wang J., 2014, Predicting unstable toughness of concrete based on initial toughness criterion, Journal of Zhejiang University Science A, 15, 2, 138-148

21. Refai T.M.E., Swartz S.E., 1987, Fracture behavior of concrete beams in three-point bending considering the influence of size effects, Report No. 190, Engineering Experiments Station, Kansas State University

22. Reinhardt H.W., Cornelissen H.A.W., Hordiuk D.A., 1986, Tensile tests and failure analysis of concrete, Journal of Structural Engineering, 112, 11, 2462-2477

23. Swartz S.E., Go C.G., 1984, Validity of compliance calibration to cracked concrete beams in bending, Experimental Mechanics, 24, 2, 129-134

24. Tada H., Paris P.C., Irwin G.R., 2000, The Stress Analysis of Cracks Handbook, Third Edition, New York

25. Tang T., Ouyang C., Shah S.P., 1996, A simple method for determining material fracture parameters from peak loads, ACI Materials Journal, 93, 2, 147-157

26. Wang C.J., Dong W., Wang Q., Wu Z.M., Qu X.H., 2016, A comparative study on propagation criterion of concrete mode I crack (in Chinese), Engineering Mechanics, 33, 5, 89-96

27. Wu Z.M., Wu X., Zheng J.J., Wu Y.F., Dong W., 2015, An analytical method for determining the crack extension resistance curve of concrete, Magazine of Concrete Research, 66, 14, 719-728

28. Xu S.L., ReinhardT H.W., 1999a, Determination of double- $K$ criterion for crack propagation in quasi-brittle fracture Part I: experimental investigation of crack propagation, International Journal of Fracture, 98, 111-149

29. Xu S.L., Reinhardt H.W., 1999b, Determination of double- $K$ criterion for crack propagation in quasi-brittle fracture, Part II: Analytical evaluating and practical measuring methods for threepoint bending notched beams, International Journal of Fracture, 98, 151-177

30. Xu S.L., ReinhardT H.W., 1999c, Determination of double- $K$ criterion for crack propagation in quasi-brittle fracture, Part III: Compact tension specimens and wedge splitting specimens, International Journal of Fracture, 98, 2, 179-193

31. Xu S.L., Reinhardt H.W., 2000, A simplified method for determining double- $K$ fracture parameters for three-point bending tests, International Journal of Fracture, 104, 181-209 